\title{
Work in Progress: Collaboration for Quality: a Librarian-Faculty Partner- ship to Assess Students' Information Literacy in Freshman Engineering
}

\section{Ms. Alison Bradley, University of North Carolina, Charlotte}

Alison Bradley graduated with a Bachelor of Arts degree from McGill University and a Master's of Science in Library Science from the University of North Carolina at Chapel Hill. She is the interim head of Research and Information Services, STEM librarian, and assistant professor at UNC Charlotte.

\section{R. Daniel Latta, University of North Carolina, Charlotte}

R. Daniel Latta is lecturer and academic advisor in the Office of Student Development and Success at the William States Lee College of Engineering. Latta is a licensed professional engineer in NC, SC and Va and professional land surveyor in NC.

Mrs. Meg Harkins, University of North Carolina, Charlotte

Meg Harkins is lecturer, freshman engineering advisor and director of the Engineering Freshman Learning Community at University of North Carolina, Charlotte's William States Lee College of Engineering. She is a licensed Professional Engineer in Pennsylvania. 
Work in Progress: Collaboration for Quality: a Librarian-Faculty

Partnership to Assess Students' Information Literacy in

Freshman Engineering 
All students majoring in engineering or engineering technology at UNC Charlotte are required to take the course Introduction to Engineering: Practices and Principles during their first semester in the program. The objective of this course is to provide new engineering students with an introduction to the profession, to encourage and excite them about the impact they could have on society, and to provide them with a glimpse of some of the tools, techniques, and skills necessary to succeed as an engineering student. For several years, students in this course have been offered the option of attending a hands-on library workshop and receiving extra credit on a related project report. Since several hundred students enroll in over 25 sections of this course each fall, the workshop format was developed as an alternative to traditional one-shot library instruction, which is not practicable on this scale. To better assess how the workshops were serving the students in these large classes, a group of instructors from the class and the engineering librarian worked together to evaluate student success with research projects and overall information literacy within the freshman engineering curriculum. The first initiative was to design a citation study assessing submitted projects for quality and variety of sources cited by students who attended a workshop with those who did not. In addition to the findings of the citation study, the entire instruction team and the librarian worked together to revise assignments and discuss new methods of providing support to all students enrolled in Introduction to Engineering, including tools like online research guides and video presentations played in class and embedded in course management software. The results of the collaboration will be assessed in the citation study and also in a comparison of year-to-year retention rates of students who attended a library session with those who did not.

Citation Analysis as a tool of assessing research instruction

Authentic assessment of student research skills is best achieved by examining their behaviors as demonstrated in their actual coursework. Several studies over recent years have used citation analysis of student work to evaluate the ability of students to select appropriate variety, types, and quantity of sources for use in assigned projects. Karen Hovde ${ }^{5}$ points out the strong benefit of citation analysis in providing "a demonstrable basis for the assertion that students are getting the instruction message", while remaining relatively non-invasive. At Drexel University, Denick, Bhatt, and Layton ${ }^{4}$ found that citation analysis gave them strong insights into their freshman engineering students' grasp of appropriate research behaviors, and also highlighted some areas that could be covered more completely in library instruction sessions in the future. Sarah Clark and Susan Chinburg ${ }^{3}$ created a model for comparing groups of students who received differing types of research instruction within a single large-scale course, allowing others to adopt their model to compare a set of students receiving library instruction with a control group that did not. Finally, Virginia Young and Linda Ackerson ${ }^{8}$ developed a program to conduct bibliographic evaluation of large numbers of student papers by trained staff members, allowing a larger sample for evaluation than a single librarian or instructor could manage individually.

Collaboration between librarians and teaching faculty

The professional literature in librarianship clearly illustrates both the need to help students develop their information literacy skills and the great potential that collaboration between instructors and librarians has to achieve this goal. Traditional library instruction introduces students to the research process, but having librarians collaborate with instructors to improve 
research-based assignments shows much stronger effects. Having librarians work with instructors on developing the assignment itself provides an essential opportunity to reach the students directly, as "students persistently focus on assignment requirements". ${ }^{7}$ Librarians can provide an important alternate point of view in developing assignments, since students often come to the reference desk for assistance with tasks that are unclear or confusing. ${ }^{6}$ Brown and Kingsley-Wilson ${ }^{1}$ describe a successful project where librarians worked with instructors to alter an existing assignment to encourage stronger research techniques, going from a scavenger-hunt style list of sources needed to more open-ended questions requiring critical thought and advanced search techniques.

What is Introduction to Engineering?

Introduction to Engineering: Practices and Principles is the first disciplinary course taught to all freshmen and transfer students entering the College of Engineering. The course is designed to introduce students to the different disciplines within engineering, as well as professional skills like engineering design and calculations. It also encourages academic, personal, and professional development, through assignments designed to foster teamwork, project planning, and oral and written communication skills within a multi-disciplinary format.

To successfully complete this course, the student must be able to:

1 Demonstrate a basic understanding of the engineering design process by successfully designing, constructing, and testing a solution that meets specific requirements and performance specifications.

2 Successfully apply knowledge of basic engineering mathematics to the problem-solving process.

3 Productively contribute as a member of a multidisciplinary team to successfully accomplish project goals.

4 Demonstrate the ability to effectively communicate in writing through the development of an engineering laboratory report.

5 Demonstrate the ability to effectively communicate orally through the development and delivery of a presentation.

6 Demonstrate a basic understanding of the need to engage in life-long learning.

7 Demonstrate a basic understanding of the need to address global, societal, contemporary, environmental and economic issues in the design process.

Students learn and apply the engineering design process. Students design, build, test, and complete specific project designs. Grades are based on how well the design process is used and how well the final designs meet design specifications and performance criteria.

What do we expect in an Introduction to Engineering paper?

The course requires the students to complete five assignments with a substantial research element. Two of the papers are the Whole Life Concepts and Disciplines parts 1 and 2, which takes the student through the decisions that lead to a specific career goal, then considers the skills, knowledge, and tools needed to reach that goal. The research involved in the Whole Life Paper should evaluate the market for a particular engineering profession, current research areas in the 
field of interest, and curricular or degree requirements for entry-level positions. The remaining three assignments are linked to hands-on design projects: constructing a small vehicle, designing a wooden beam, and building a voltage divider. Each project provides a varying level of direction as to the research required: some indicate the general area to be researched, others simply ask for a certain number of "reliable sources", and one gives a specific list of related topics to be researched by each student on the team.

The Introduction to Engineering course is required during the first semester a student is enrolled in the program: typically, this is the fall semester of freshman year, but students who enter the major midway through the year (or who do not pass on their first attempt) may enroll in the spring. Aside from transfer students, when taking this course most students will only have the research comprehension and skills they developed in high school. Although they will need to continue learning how to properly conduct research at a college level as they progress through the degree program, they are expected to meet a baseline level of ethical and effective research to pass the course. According to the Common Core State Standards, 12th grade students should be capable of researching a topic as follows:
CCSS ELA Literacy-W.11-12.8 Gather relevant information from multiple authoritative print and digital sources, using advanced searches effectively; assess the strengths and limitations of each source in terms of the task, purpose, and audience; integrate information into the text selectively to maintain the flow of ideas, avoiding plagiarism and overreliance on any one source and following a standard format for citation. (http://www.corestandards.org/ELA-Literacy/W/11-12) ${ }^{2}$

It is essential that the students recall and understand the plagiarism guidelines they were taught in high school. The library workshop is designed to expand the students' understanding of research beyond the high school level and to support those who may have limited development of this skill.

Format and evolution of the library workshop

Before the current librarian took over as liaison for engineering in 2008, the workshops were designed as traditional bibliographic instruction sessions. The librarian presented a wide range of the engineering databases available at this institution, and demonstrated searches in a selection of these as well as the library catalog, using keywords related to the next research assignment due. For first semester freshmen, this typically overwhelmed them with information: they weren't ready to use intensive search tools like Compendex, and with no immediate practical applications the students were not likely to remember that this or the other research tools existed in the future. As the librarian and instructors continued to work together to focus on the perceived shortcomings in the students' submitted research, it was decided to spend more time on conceptual ideas like proper citation and ethics of information use, evaluation of web sources, and to focus narrowly on the most immediately useful library tools for the assignment at hand.

Assessment and analysis 
Although anecdotal responses and post-class student surveys offered positive feedback about the workshops, a more comprehensive assessment was designed to determine if the workshops had the intended effect. Librarians and course instructors worked together to create an ongoing rigorous evaluation of the program, comparing the quality and relevance of citations in projects submitted by the students who attended the workshops with those who did not. Papers are selected by course section to create a fair basis of comparison between the control group who did not attend a workshop and the students who did attend. Since this is a large course with many sections taught by multiple instructors, comparing students within individual sections helps ensure that they have received the same instructions and guidance regarding the assigned work (apart from their participation or non-participation in the library workshops). The assessment of the sources includes number of sources cited, types of material (article, website, book, etc.), and reliability of source. Results of the analysis are shared and discussed amongst the research team and with other Introduction to Engineering instructors to help plan for future iterations of the course and the library workshop program.

The current project is an extension of a successful pilot study conducted over the 2011-12 academic year. During Fall 2011, 485 students were enrolled in 19 sections of Introduction to Engineering. Eight library workshops were scheduled, and 55 students attended. The workshop focused on selecting appropriate search tools, brainstorming keywords, and proper citation style. During Spring 2012, 239 students were enrolled in 10 sections of Introduction to Engineering. Six workshops were scheduled, and 66 students attended. The final project with citations was a group paper, so projects where one, some, all, or any students in the group attended were compared with projects where no students in the group attended.

In the pilot analysis, the study showed that students who attended a workshop were generally more successful than those who did not, but that they still relied heavily on sources that the instructors and librarian agreed were inappropriate for college level research. In fall 2011, students who attended a workshop used a smaller proportion of unreliable websites, but still cited large numbers of inappropriate websites (see Figure 1).

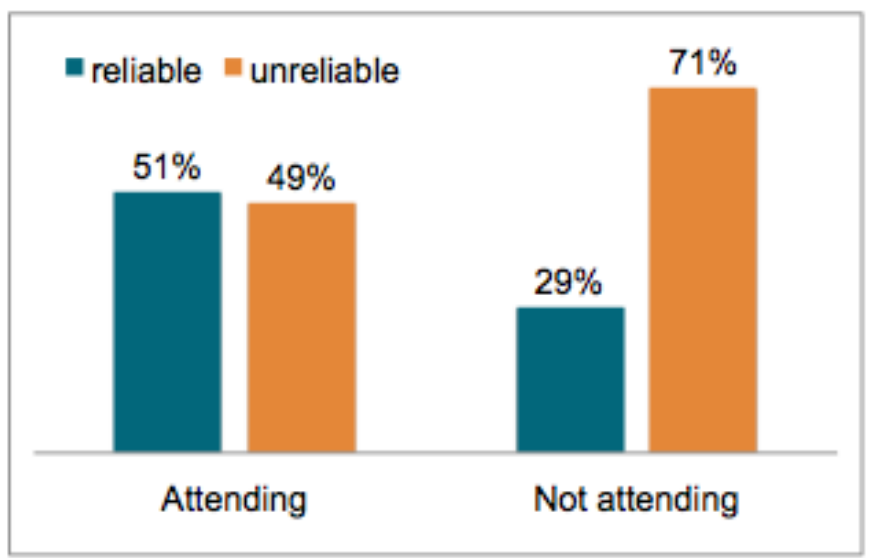

Figure 1: Reliable and unreliable websites as percentages of total web citations

In spring 2012, workshop attendance correlated with use of a larger variety of sources. All papers that cited an article or a standard had at least one student attend a workshop, while groups with no one attending used only books and websites (see figure 2) 


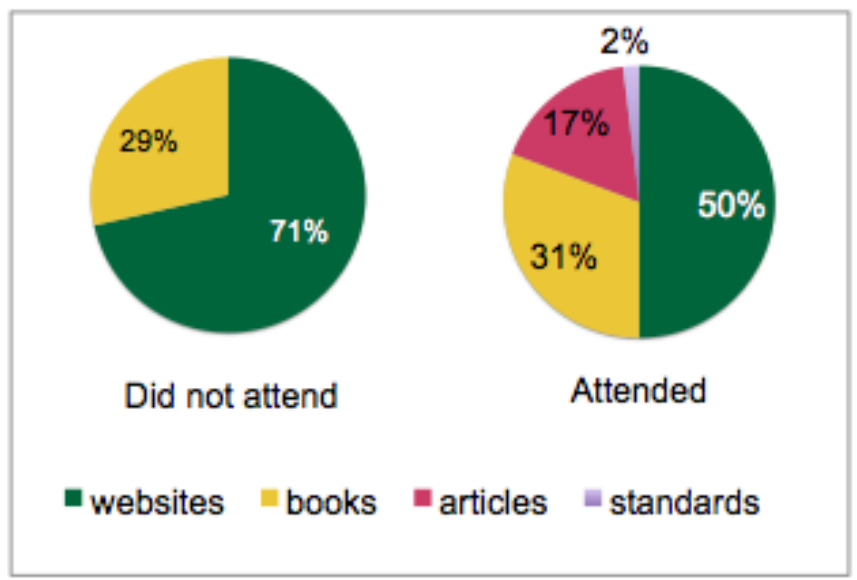

Figure 2: Variety of sources used

In the expansion of this study for the 2012-13 academic year, a graduate research assistant will conduct ongoing analysis of works cited and evaluate work submitted in past semesters to create an expanded picture of the state of student research in this course over time. This should allow the librarian and the instructors to focus on discussing the results of the analysis and creating shared learning outcomes for student research throughout the Introduction to Engineering course. The engineering librarian will create a scoring rubric for analyzing citations as submitted by students in the selected sections of Introduction to Engineering, and will train the graduate student on the accurate use of the rubric. The graduate student will score the reference lists of evaluated papers, and create sets of data to examine variation between the students who attended a workshop with those who did not.

References

1 Brown, C., \& Kingsley-Wilson, B. (2010). Assessing organically: turning an assignment into an assessment. Reference Services Review, 38(4), 536-556

2 Common Core State Standards. (2012). http://www.corestandards.org/ELA-Literacy/W/11-12

3 Clark, S., and Chinburg, S. (2010). "Research Performance in Undergraduates Receiving Face to Face versus Online Library Instruction: A Citation Analysis." Journal of Library Administration 50 (5-6) (August 10): 530-542.

4 Denick, D., Bhatt, J. and Layton, B.. (2010). Citation Analysis of Engineering Design Reports for Information Literacy Assessment. http://idea.library.drexel.edu/handle/1860/3475.

5 Hovde, K. (2000). "Check the citation: library instruction and student paper bibliographies." Research Strategies 17 (1) (March): 3-9.

6 Kenedy, R., \& Monty, V. (2011). Faculty-Librarian Collaboration and the Development of Critical Skills through Dynamic Purposeful Learning. Libri: International Journal of Libraries \& Information Services, 61(2), 116-124.

7 O'Connor, L., Bowles-Terry, M., Davis, E., \& Holliday, W. (2010). "Writing Information Literacy" Revisited Application of Theory to Practice in the Classroom. Reference \& User Services Quarterly, 49(3), 225-230. 
8 Young, V. E., and Ackerson, L. G. (1995). "Evaluation of student research bibliographies: refining evaluation criteria." Research Strategies 13 (2): 80-93. 